\title{
One Health Approach in Traditional Milk Production as a Part of Steps towards SDGs
}

\author{
Marija Jevtic ${ }^{1}$, Branislava Belic ${ }^{2}$, Danica Glavas - Trbic $^{2}$
}

\begin{abstract}
The production of milk and cheese assumes activities in the field of agricultural production, veterinary health, and the use of milk and dairy products has public health significance, and can be viewed through the "one health" concept. The aim of the paper is to underline public health and sustainability significance of interconnection among agriculture, veterinary and technology. Production of hard cheese with added value from milk produced in organic and self-sustaining systems research the risks, advantages and possibilities of traditional cheese production and focused on creating conditions for organic milk and hard cheese with added value production, with precisely defined conditions: isolating land plots, livestock farms and processing facilities from possible sources of pollution, water quality, harmonized development of plant and animal production and the capability of producers for organic agriculture with the obligation to constantly innovate knowledge. The new products ensure the employment and livelihood of people in the countryside, the economic prosperity of small family farms, link the activities in the field of veterinary health and agricultural production, contribute to the development of risk-management technology, healthy chooses and compatible with SDGs.
\end{abstract}

Keywords: One Health approach, Traditional Milk Production, sustainability, Healthy Choices, SDGs

\section{Introduction}

The steady growth of population and the increased demand for food have caused various changes in the methods of agricultural production. Research shows that a technologically intensive and highly productive food production system leads to many negative effects of both economic and social nature, especially to environmental problems. A too high degree of reliance on monoculture and agricultural inputs have a negative impact on food quality and safety, environment and rural development. Hodge sums up certain negative trends in modern agriculture that lead to a reassessment of the long-term sustainability of such a production system. According to him, agriculture has been brought to a situation where it uses inputs from farther sources in both spatial and sector terms; drawing growingly larger volumes of the needed energy from nonrenewable resources; depending on a decreasingly reduced gene base and having growingly increased (negative) impact on the environment (12).

This is especially evident from its growing reliance on the chemical industry (in the form of fertilizers and pesticides), its dependence on subsidies and support to prices and increasing negative externalities it produces, such as habitat degradation, and destruction of various animal and floral species, environmental pollution and risk to human health and well-being. 
The aforementioned negative consequences have increased the need to find new production systems.

Alternative systems of agricultural production are most typically categorized as sustainable agriculture, shifting the focus towards the organic production which is primarily distinguished by a different approach to the environment (14).

Nowadays, organic production is experiencing increasing expansion globally. EU countries and their neighbors are placing organic production to a higher level and organic products are a centerpiece of the sustainable development strategy. Lampkin and Padel (1994) define organic production as both philosophy and production system the goal of which is to create integrated, human, economically sustainable and environmental-oriented agriculture (7).

Organic agriculture strives to maximize the utilization of renewable resources produced on the farm and is a system of managing ecological and biological processes for the purpose of obtaining an acceptable level of crop yield, animal yield and nutrient levels needed for human consumption. Despite the differences in defining the concept of organic agriculture, the main objective of such a production system is a sustainable agricultural production system (14).

The term "sustainable" is used in a broader sense, including economic, social and natural sustainability (13). Sustainability is also observed at the level of the individual producer and the level of the entire community as well. Being a sustainable production system, organic agriculture has a capacity to enhance soil fertility, biodiversity and sustainability of agricultural production; preserve natural resources; improve agronomic and economic performances; make yield more stable, especially in high-risk, tropical eco-systems; achieve better food quality and safety; provide access to attractive markets of certified products; create new partnership relations within the value chain, as well as strengthen self-confidence and autonomy among farmers (6).

In order to start organic production, it must meet some precisely defined terms isolation of land plots, livestock farms and processing capacities from possible sources of pollution, then water quality, coordinated development of crop and livestock production and competence of producers for organic agriculture including the obligation to constantly innovate their knowledge.

According to Regulation (CE) 834/2007, organic agriculture is defined as a "system of permanent management the goal of which is to produce high-quality food products" (5). Organic is considered a reference for the environment and at the same time a form of permanent consumption of products which are safer for consumers' health, natural, of higher nutrition value, can be produced at a lower cost and sold at higher prices. Customers who prefer the products related to better quality and healthier living are not price-sensitive. In the markets well-supplied with organic food, consumers buy organic products mostly for health-related reasons or because such food tastes better.

Organic production as an overall system of managing agricultural and food production, combined with environmental protection while preserving biodiversity and natural resources is the basis for high quality and safe food, social security and sustainable development (Law on Organic Production 30/2010 and 17/2019) (15, 16).

Organic milk and cheese with added value are a healthier and safer alternative for the consumer. Animals that produce organic milk are fed with organic food, gazing in 
pesticide-free fields and kept in humane conditions, which is scarce when it comes to livestock farming in the traditional production. Also, in order to produce dairy products in compliance with food safety standards, appropriate hygiene conditions, storing and distribution as well as permanent control and education of producers must be ensured. Consumption of dairy products has recently been recorded as related to the demand for traditional products, i.e. the products with an indication of geographic origin, coming from small farms and perceived by the consumer as an embodiment of "healthy" food $(10,11)$.

It is well known that milk and dairy products in the food pyramid are represented with $10 \%$ of the total energy needs. Traditional production in local capacities is of particular importance, especially with regard to sustainability.

The production of milk and cheese assumes activities in the field of agricultural production, veterinary health, and the use of milk and dairy products has public health significance, and can be viewed through the "one health" concept.

Small farms i.e. family farms engaged in livestock farming and milk production have a substantial share in the local market of milk and dairy products. Minor milk producers who cannot compete for state subsidies cooperate only with small-capacity dairies thus surviving on the market because large-sized diaries do not recognize them (8). Advantages of small and middle-sized producers are in the fact that they can react to market fluctuations with an adequate range of products within a short period of time (4, 11). Due to a low level of utilization of machinery and production commercialization, and due to insufficient financial capacities to upgrade the production, milk production by small-sized producers is actually based on traditional production which largely meets the standards of organic production.

The aim of the paper is to confirm the public health significance of interconnection among agriculture, veterinary and technology, to provide a safe product for people.

\section{Results and Discussion}

The research was conducted through a multidisciplinary national project named "Production of hard cheese with added value from milk produced in organic and selfsustaining systems" No TR31095 in the Republic of Serbia. It investigated production of hard cheese with added value from milk produced in organic and self-sustaining systems: the risks, advantages and possibilities of traditional cheese production.

The research is focused on creating conditions for organic milk and hard cheese with added value production, with precisely defined conditions: isolating land plots, livestock farms and processing facilities from possible sources of pollution, water quality, harmonized development of plant and animal production and the capability of producers for organic agriculture with the obligation to constantly innovate knowledge. Milk from organic production is obtained from non-stressed animals because they are kept in good conditions for their well-being, does not contain antibiotics and other harmful residues, and contains more vitamins and omega 3 fatty acids. Most of the year the cows graze, use clean air and sun, eat green mass, silage, sage and hay.

The nature of dairy products has changed dramatically in recent decades, with an 
increased orientation towards the production of "value added products", some of which are segmented into the "health and wellness" market (4). Cheese is a rich source of essential nutrients, in particular, proteins, bioactive peptides, amino acids, fat, fatty acids, vitamins and minerals. The popularity of cheese is enhanced by its healthy and positive image. The role of milk and dairy products in human nutrition has been increasingly debated in recent years. Nevertheless, cheese consumption in Serbia is very small and amounts $2.76 \mathrm{~kg} /$ per capita/per year $(4,9)$. Furthermore, investigated hard cheese belonged to the group of hard, full fat cheese and could provide a wide range of essential nutrients to the diet. It is a good source of high-quality protein, amino acids, fat, fatty acids and energy essential for growth and maintenance of various body functions. Cheese is very suitable source of protein for people who do not eat meat and are considered to be one of the main food groups important in a healthy balanced diet (9). The unique nutrients and important bioactive compounds of hard cheese make it a product of added value. The greatest impact on the quality of the final product had variables connected to microbiological quality. Microbiological safety is achieved by focusing on the prevention, adhering to the good hygiene practice and due to good control of ripening conditions.

Quality control of dairy products is particularly important for public health and safety. The quality of cheese is influenced by its composition, especially moisture content, $\mathrm{NaCl}$ concentration, $\mathrm{pH}$, moisture in nonfat substances (MNFS), and percentage fat in dry matter (FDM). Important aim of the project was focused on investigation of chemical parameters during cheese ripening, including determination of amino and fatty acid profile of mature cheese.

Microorganisms play essentials role in the manufacture and ripening of cheese. According to that, the objective was to evaluate the microbiological safety of hard type cheese during ripening. Cheeses are currently considered to be one of the safest foods consume, but pathogenic bacteria that can be transmitted by dairy products, including cheese, are important to the dairy industry. (4).

The project titled "Production of hard cheese with added value from milk produced in organic and self-sustaining systems" has been implemented at farms and dairies on the territory of the Republic of Serbia in the period 2011-2019, and the research was focused on the creation of conditions for organic milk production and production of hard cheese with added value, the local production of which is scarce in the market of the Republic of Serbia. Initial research in the existing conditions of traditional production lead to the period of conversion and eventually to organic production. The primary goal was to create conditions for organic production of fresh milk and to produce hard cheese with added value from such milk in conditions of organic and self-sustainable production. Products with added value are all those products which, in addition to standards established by the law on food safety and quality, meet some additional requirements. The added value of products arises from their growing nutritional and commercial value including very often the products of organic production the products with an indication of geographic origin. Consumer awareness of production value has significantly increased and enticed their demand for healthy and high-quality products. One of the most important factors affecting the quality and yield of cheese is the composition of milk, particularly the concentration of fats and casein (2).

During the project, new technology in primary milk production was applied using 
nutrition suitable for organic production. An adequate manner of keeping, milking, applying HACCP concept in primary production ensures the highest quality of raw milk. The high quality of raw milk ensures more favorable economic results in a way that farms are generally self-sufficient with respect to manure and other natural inputs so that the cost price of milk from organic production will be lower. The production of hard cheese with added value will supply the market of the Republic of Serbia with a new product which is otherwise not available except for the imported ones and which is of a higher health, nutrient and organoleptic value on one hand, and the quality of which can affect the sustainable development on the other hand.

Based on analyses of milk produced in organic production, the results have been reached that in most cases (on average) the number of somatic cells is lower in milk coming from the organic farms. Organic milk produced by grazing cattle contains a higher level of polyunsaturated fatty acids which are important for health. In addition to omega 3 fatty acids, organic milk also contains a higher level of some vitamins such as A, E and C. Milk fat is a good source of retinol, alpha-tocopherol and beta-carotene, which contribute to antioxidant activity, in both biological tissues and food. Since fat in cheese has not been removed, biologically active ingredients have remained.

Well-aged hard cheese has a higher digestibility, higher concentration of calcium which affects the formation and protection of bones and teeth, prevention of osteoporosis and hypertension. Also, the new technology of production of hard cheese with added value makes it possible for small-sized producers to rationally produce cheese from raw milk (in small-capacity plants) and cheese made of pasteurized milk in the industry (large industrial plants). Because during the research in cheese technology intended for smallsized producers pasteurization is not used, this will result in a lower cost of energy, labor and equipment, and these are some additional effects which must result in a lower production price of a ready-to-use product.

The production of hard cheese with added value which requires the period of ageing of at least 60 days, of a granular structure and which is used for cutting and grating and which is not produced by any of the dairies in the Republic of Serbia will expand the range of cheese products in this country. The advantage is in both quality and economic profitability, which is of special importance for organic and self-sustaining systems. Whey, as a by-product, has been partly used in products such as probiotic beverages and albumin cheese and partly as pig feed. The use of whey does not pollute the environment while at the same time the high-quality dairy and meat products are being produced.

In the production on small registered agricultural households (RAHs) in Vojvodina, human and cultural resources are used in addition to natural resources, which are recognized as a factor of added value. The number of consumers that are looking for a healthier, fresh and unique product, where production and sales are close and in line with its requirements, is constantly increasing.

Consumers in EU recognize quality of cheeses that are produced on small agricultural households and sold at an open market. EU agricultural policy stimulates a certain form of extensive agricultural production that contributes to the protection of the environment, biodiversity and rural areas.

Many of the described products are missing or insufficient on the market. By investing in premises and equipment on RAHs, conditions in the technical and technological area 
have been created for the production of the described products. This facilitates production, and increases the quality and quantity.

There is a need for branding certain cheeses from Vojvodina that are produced on RAHs. Formation of added value as a result of consumer skills and territorial strategies is becoming increasingly important. Adding value to products strengthens the territorial capacity of the area, improves the image of the territory and increases employment. Some of the cheeses of such a kind are shown in Figures 1 and 2, and they were produced in the territory of AP of Vojvodina from cow and goat milk.

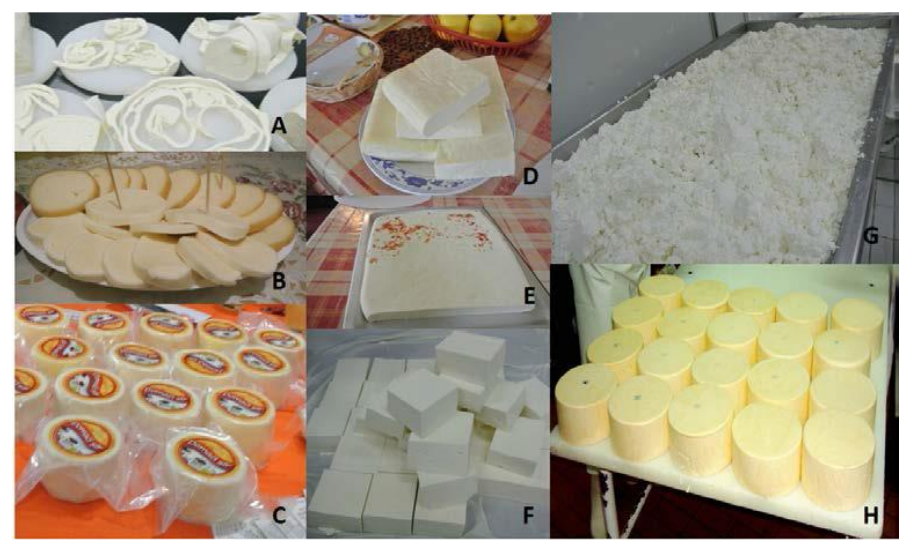

(A) Layered cheese, (T.S) Kikinda, (B) Layered cheese, (T.S) Kikinda, (C) Kashkaval cheese, (M.R.) Rusko selo, (D) Drenched cheese, (L.J.) Obrovac, (E) Drenched cheese, (L.J.) Obrovac, (F) Slice cheese, (L.J.) Obrovac, (G) Cottage cheese, (M. I.) Vrbas, (H) Semi-hard cheese, (P.R.) Čurug (2)

Figure 1. Cow cheeses from registered agricultural households in Vojvodina (2)



(A) Kashkaval cheese, (M.C.) Karađorđevo, (B) Smoked cheese and cheese with spices (J.B.) Srpski Krstur, (C) Slice cheese, (K.D.) Srbobran, (D) Hard cheese, (E. K.) Kanjiža (2)

Figure 2. Goat cheeses from registered agricultural households in Vojvodina (2) 
Milk from organic production is obtained from non-stressed animals because they are kept in good conditions for their well-being, does not contain antibiotics and other harmful residues, and contains more vitamins and omega 3 fatty acids. Most of the year the cows graze, use clean air and sun, eat green mass, silage, sage and hay.

In addition to the above stated, the production of raw organic milk and hard cheese with added value is generally significant in human nutrition due to the already mentioned abundance of certain vitamins (such as A, E and C) against the conventionally produced food products of the same kind.

Organic milk contains more omega 3 fatty acids than conventional milk. Organic milk and cheese cannot contain antibiotic residues, because they are not used in the treatment of animals, as well as other harmful residues. Organic milk and dairy products are obtained from animals which are not under stress because the treatment of animals in this system presupposes their wellbeing and good life. Among other things, most of the year the cows spend in the pasture, in the fresh air and sun and they feed on green mass, silage, hay and haylage (1).

Mastitis as an unsurmountable problem in conventional production, which has a negative impact on the quality of milk and its health value, has been reduced to a minimum or even non-existent in organic production. This study shows how to overcome this problem by treating animals differently which includes their well-being, proper milking and, if needed, medical treatment based on homeopathic medicines.

Given the fact that Serbia is getting ready to join the EU, one should bear in mind that ecological principles of organic production enable better responses to the challenges as they achieve environmental protection of high quality, better adaptation to climatic changes, high quality biodiversity and ecosystem management, sustainable production, high quality and safe food, better economic efficiency and sustainable rural development. It can be said that one of the primary goals of organic production is the production of food of high nutrition value as well as the development of sustainable agriculture while at the same time preserving the ecosystem. Cheese labelled as "Organic product" is a confirmation of quality and it is a product coming from organic production that an average consumer in Serbia relates to good health. Quality and health go hand in hand with each other carrying out a mission of the producers of organic products and, within this context, there are multiple reasons to raise the development of organic agriculture, and especially livestock farming in Serbia, to a higher level.

There is an increasing awareness of the high levels of biodiversity and the important role it plays in enhancing the sustainability of low-input dairy production systems. Conventional agroecosystems are poor in biodiversity and significantly contributed to the reduced number of breeds and genetic diversity of domestic animals. Although, adopted numerous acts and measures to protect autochthonous breeds and genetic resources, many are still facing the threat of the complete disappearance. Organic farming represents agricultural practice that could contribute to the preservation of biological diversity and breeding of cows with the most desired milk quality attributes (1). 


\section{Conclusion}

Agriculture production directly affects biodiversity through different cultivation practices. Organic production as an alternative production system, categorizes as sustainable agriculture with different environmental approaches, could be useful in conservation of biodiversity. It represents an overall system of agriculture management preserving the environment while not exploiting natural resources, keeping biodiversity and at the same allowing production of high-quality and safe food for consumers, social safety and economic stability for producers as well as sustainable development in general. The production of milk and cheese assumes activities in the field of agricultural production and veterinary health. The use of milk and dairy products has public health significance and can be viewed through the One Health concept. The nature of dairy products has changed dramatically in recent decades, with an increased orientation towards the production of "value added products", some of which are segmented into the "health and wellness" market.

Organic milk and cheese with added value are considered by consumers as a healthy and safer alternative. Production of hard cheese with added value from milk produced in organic and self-sustaining systems research the risks, advantages and possibilities of traditional cheese production.

Farmers have been encouraged to consider the effects of intensification on farm biodiversity and importance of biodiversity in cheese production is increasingly apparent. It is important to develop the knowledge base on livestock biodiversity to help to maintain local species and breeds that may otherwise become extinct.

Greater primary milk production ensures the employment and livelihood of people in the countryside, the economic prosperity of small family farms and improves the quality of life and respecting traditional approaches and local customs that are in line with public health recommendations and One Health concept.

The new products also ensure the economic prosperity of small family farms, link the activities in the field of veterinary health and agricultural production, contribute to the development of risk-management technology, healthy chooses and compatible with SDGs.

\section{Acknowledgements}

This paper represents the part of the research within the projects TR31095 Production of hard cheese with added value from milk produced in organic and selfsustaining systems financed by the Ministry of Education, Science and Technological Development of Republic of Serbia. Project period is 2011-2019.

\section{References}

Anka Popovic-Vranjes, Snezana Paskas, Zsolt Becskei, Marija Jevtic, Sasa Krstovic (2018): The Impact of Organic Agriculture on Biodiversity Conservation and Milk Quality for Traditional Cheese Production, Contemporary Agriculture, 67(1): 58-64. 
Anka Popovic-Vranjes, Sasa Krstovic, Marija Jevtic, Zeljka Jurakic, Katarina Strugar (2017): Technological Process of Added Value Cheese Making on Registered Agricultural Households in Vojvodina, Biotechnology in Animal Husbandry, 33(4): 449-463.

Anka Popovic-Vranjes, Snezana Paskas, Anka Kasalica, Marija Jevtic, Milka Popovic, Branislava Belic (2016): Production, composition and characteristics of organic hard cheese, Journal Biotechnology in Animal Husbandry, 32(4): 383-392.

Anka Popovic Vranjes, Snezana Paskas, Marija Jevtic, Anka Kasalica, Branislava Belic, Milka Popovic (2018): Nutritional and Energetic Value of Hard Cheese, Biotechnology in Animal Husbandry, 34(2): 217-227.

Council Regulation (EC) No 834/2007.

Kilcher, L. (2007): How organic agriculture contributes to sustainable development, JARTS, Supplement 89, University of Kassel at Witzenhausen, Germany, 31-49.

Lampkin, N., Padel, S. (1994): The Economics of Organic Farming, an International Perspective, CAB International, London.

Milic, D., Glavas-Trbic, D., Tomas Simin, M., Zekic, V., Novaković, T., Popov, M. (2019): Economic characteristics of sour cream production in small-scale dairy processors in Serbia, Economic of Agriculture, 66 (3): 787-798.

Popovic Vranjes, A., Popovic, M., Jevtic, M. (2015): Raw Milk Consuption and Health. Srp Arh Celok Lek, Jan-Feb; 143(1-2): 87-92.

Popovic Vranjes, A., Pejanovic, R., Cvetanovic, D., Jevtic, M., Popovic, M., Glavas-Trbic, D., Jez, G. (2012): Application of holistic methods in organic milk analysis, Mljekarstvo, 62(4): 284-290.

Popovic Vranjes, A., Krstovic, S., Jurakic, Z., Saran, M., Vlahovic, B., Popovic, M. (2017): Models of smallsized cheese production plants, Agroekonomika, 76: 67-78.

Rigby, D., Caceres, D. (2001): Organic farming and the sustainability of agricultural systems, Agricultural Systems, 68: 21-40.

Tomas Simin, M., Jankovic, D. (2014): Applicability of diffusion of innovation theory in organic agriculture, Economics of Agriculture, 2: 517-529.

Tomas Simin, M., Rodic, V., Glavas - Trbic, D. (2019): Organic agriculture as an indicator of sustainable agricultural development: Serbia in focus, Economic of Agriculture, 66 (1): 265-280.

Law on Organic Production, Official Gazette of the Republic of Serbia, No. 30/2010.

Law on Organic Production, Official Gazette of the Republic of Serbia, No. 17/2019. 